\title{
Inducible nitric oxide synthase (NOS2) knockout mice as a model of trichotillomania
}

\author{
Plinio C Casarotto ${ }^{\text {Corresp., }}{ }_{1,2}$, Caroline Biojone ${ }^{1,3}$, Karina Montezuma ${ }^{3}$, Fernando Q Cunha ${ }^{2}$, Samia R L Joca ${ }^{3}$, \\ Eero Castren ${ }^{1}$, Francisco S Guimaraes ${ }^{2,4}$ \\ ${ }^{1}$ Neuroscience Center, University of Helsinki, Helsinki, Finland \\ 2 Department of Pharmacology, Ribeirão Preto Medical School, University of São Paulo, Ribeirão Preto, São Paulo, Brazil \\ 3 Department of Physics and Chemistry, School of Pharmaceutical Sciences of Ribeirão Preto, University of São Paulo, Ribeirão Preto, São Paulo, Brazil \\ 4 NAPNA: Center for Interdisciplinary Research on Applied Neurosciences, University of São Paulo, Ribeirão Preto, São Paulo, Brazil \\ Corresponding Author: Plinio C Casarotto \\ Email address: plinio.casarotto@helsinki.fi
}

Background: trichotillomania (TTM) is an impulse control disorder characterized by repetitive hair pulling/trimming. Barbering behavior (BB) observed in laboratory animals is proposed as a model of TTM. The neurobiological basis of TTM is unclear, but involves striatal hyperactivity and hypoactivation of the prefrontal cortex.

Methods: in this study, we evaluated the BB in knockout mice for the inducible isoform of nitric oxide synthase (NOS2KO) and the consequences of silencing this enzyme in PC12 cell differentiation.

Results: NOS2KO exhibit exacerbated BB, starting 4 weeks of age, and increased repetitive movements compared to wild-type mice (WT). The expression of BB was attenuated by repeated treatment with clomipramine, a clinically approved drug to treat TTM in humans, or memantine, an antagonist of NMDA receptors, as well as partial rescue of NOS2 expression in haploinsufficient animals. The silencing of NOS2 expression reduced the MAP2 (microtubule-associated protein 2) levels in activity-induced differentiated PC12 cells.

Discussion: our data led us to propose that NOS2 is putatively involved in the neuronal maturation of the inhibitory afferent pathways during neurodevelopment, and such inadequate inhibition of motor programs might be associated to the observed phenotype. 
2 Title: Inducible nitric oxide synthase (NOS2) knockout mice as a model of trichotillomania

3 Running title: NOS2.KO as a model of trichotillomania

4

5 Plinio C Casarotto ${ }^{1,2 *}$, Caroline Biojone ${ }^{1,3}$, Karina Montezuma ${ }^{3}$, Fernando Q Cunha ${ }^{2}$, Samia RL

6 Joca $^{3}$, Eero Castren ${ }^{1}$, Francisco S Guimaraes ${ }^{2,4}$

7

8 1: Neuroscience Center, University of Helsinki, Helsinki, Finland.

9 2: Department of Pharmacology, Ribeirão Preto Medical School, University of São Paulo, 10 Ribeirão Preto, SP, Brazil.

11 3: Department of Physics and Chemistry, School of Pharmaceutical Sciences of Ribeirão Preto, 12 University of São Paulo, Ribeirão Preto, SP, Brazil.

13 4: NAPNA: Center for Interdisciplinary Research on Applied Neurosciences, University of Sao 14 Paulo, SP, Brazil.

15

$16 *$ corresponding author:

17 Dr. Plinio Cabrera Casarotto

18 plinio.casarotto@helsinki.fi

19

20

21

22 


\section{Abstract}

24 Background: trichotillomania (TTM) is an impulse control disorder characterized by repetitive

25 hair pulling/trimming. Barbering behavior (BB) observed in laboratory animals is proposed as a

26 model of TTM. The neurobiological basis of TTM is unclear, but involves striatal hyperactivity

27 and hypoactivation of the prefrontal cortex.

28 Methods: in this study, we evaluated the BB in knockout mice for the inducible isoform of nitric 29 oxide synthase (NOS2 KO) and the consequences of silencing this enzyme in PC12 cell 30 differentiation.

31 Results: NOS2 KO exhibit exacerbated BB, starting 4 weeks of age, and increased repetitive movements compared to wild-type mice (WT). The expression of BB was attenuated by repeated treatment with clomipramine, a clinically approved drug to treat TTM in humans, or memantine, 34 an antagonist of NMDA receptors, as well as partial rescue of NOS2 expression in 35 haploinsufficient animals. The silencing of NOS2 expression reduced the MAP2 (microtubule36 associated protein 2) levels in activity-induced differentiated PC12 cells.

37 Discussion: our data led us to propose that NOS2 is putatively involved in the neuronal maturation of the inhibitory afferent pathways during neurodevelopment, and such inadequate inhibition of motor programs might be associated to the observed phenotype. 
46

47

48

49

50

51

52

53

54

55

56

57

58

59

60

61

62

63

64

65

66

67

68

69

70

71

72

73

74

75

76

\section{Introduction}

The cortico-striato-thalamo-cortical circuitry (CSTC) is a series of reverberatory loops that control motor programs. The glutamatergic neurotransmission plays a crucial role in both afferent and efferent pathways in prefrontal cortex and striatum, two core structures in the regulation of CSTC (Langen et al., 2011a,b). In this scenario, nitric oxide (NO) plays a major part, not only regulating the release of glutamate but also in the migration and maturation of neuronal cells in the cortex. This later feature of NO is apparently mediated by the inducible isoform of nitric oxide synthase (NOS2) (Arnhold et al., 2002).

Malfunctions of specific parts of the CSTC are speculated to be involved in the neurobiology of several motor and impulse control disorders, such as obsessive-compulsive disorder, Tourette's syndrome, and of interest to the present study, trichotillomania (Langen et al., 2011b,a).

Trichotillomania (TTM) is an impulse control disorder characterized by a distressing urge for hair pulling or trimming, affecting 1-3.5\% of the population (Christenson, Pyle \& Mitchell, 1991; American Psychiatric Association, 2013). Nowadays the pharmacotherapy for TTM is based on treatment with the serotonin reuptake inhibitor clomipramine (Swedo et al., 1989; Swedo, Lenane \& Leonard, 1993; McGuire et al., 2014). Recent studies also indicate that the glutamatergic neurotransmission modulator, $\mathrm{N}$-acetyl-cysteine, is effective in alleviating the symptoms of TTM (Grant, Odlaug \& Kim, 2009). Other drugs, such as atypical antipsychotic olanzapine, have shown success in placebo-controlled trials (Van Ameringen et al., 2010).

Neuroimaging studies indicated increased gray matter volume in striatum, amygdalohippocampal formation, and multiple cortical regions (including the cingulate, supplemental motor cortex, and frontal cortex) of patients with TTM (Chamberlain et al., 2009). This increase in gray matter was associated with a relatively decreased activity in cortical structures, and hyperactivity in the striatal region (Fineberg et al., 2010). Despite these findings, the neurobiology of TTM is not completely understood.

Animal models for the investigation of neurobiological aspects of TTM, as well as the search for new therapies, rely on the observation of barbering behaviors (BB). In laboratory and captive animals, BB is characterized by pulling or trimming of fur or whiskers (Garner et al., 2004). Some transgenic strains, e.g. SAPAP3 and SLITRK5 knockouts, display compulsive/repetitive behavior, like excessive grooming (Welch et al., 2007; Shmelkov et al., 
77 2010), however no specific $\mathrm{BB}$ has been described for them. Interestingly, SAPAP3 is a 78 structural protein crucial for the proper docking of glutamatergic receptors (Welch et al., 2007).

79

80

81

82

83

84

85

86

87

88

89

90

91

92

93

94

95

96

97

98

99

100

101

102

103

104

105

106

107

In the present study, we describe the BB observed in NOS2 KO mice, and the effects of chronic treatment with clomipramine or memantine (a noncompetitive antagonist of NMDA receptors), as well as the partial rescue of NOS2 expression in haploinsufficient mice.

\section{Methods}

Animals: male and female NOS2 knockout (NOS2 KO; matrixes purchased from Jackson Lab \#2596, Bar Harbor, ME, USA), rederived into C57BL6/j background (WT, used as controls), were bred in the colony established in the Department of Genetics - Ribeirão Preto School of Medicine at the University of São Paulo. Unless otherwise stated, the adult animals (8 weeks old) were transported to the animal facility of the Department of Pharmacology one week prior to the beginning of experiments. The animals were housed in groups (3-6/cage) and undisturbed (except for normal cage cleaning) with food and water available ad libitum except during experimental procedures. All efforts were made to minimize animal suffering. All protocols were approved and are in accordance with international guidelines for animal experimentation $(146 / 2009)$.

Drugs: clomipramine hydrochloride (clomipramine; Sigma-Aldrich, São Paulo, Brazil) and memantine hydrochloride (memantine; Sigma-Aldrich, São Paulo, Brazil) were used. All drugs were dissolved in the drinking water (memantine at $0.006 \mathrm{mg} / \mathrm{ml}$ and clomipramine at 0.06 $\mathrm{mg} / \mathrm{ml}$ concentration). The solutions were changed every 2 days, and the amount of liquid consumed was determined by changes in the bottle weight. The total volume was divided by the number of animals in each cage, and an average of $4.9 \mathrm{ml} /$ day/animal was stably observed throughout the experiments.

Actimeter test (ACTM): the actimeter test was performed to evaluate general locomotor activity as well as repetitive behaviors. The detection of repetitive behavior relies on a specific pattern of interruption of infrared beams and comprises stereotypies and grooming. Briefly, the first beam is interrupted, followed by two interruptions of the adjacent one while the first beam remains obstructed. This apparatus consisted of two frames of 32 infrared beams in a square 
108 arena (Panlab-Harvard Apparatus, Barcelona, Spain). The animals were allowed to explore the 109 arena for $15 \mathrm{~min}$.

111 Barbering behavior (BB): the animals were scored regarding the state of the whiskers and fur, 112 hair trimming or plucking. The score (table 1) was based on Garner and colleagues (2004) body 113 map for BB. The sum score for the absence of whiskers/fur in snout, eye surroundings, forehead, 114 chest, neck, and back was determined every 5 days by an observer blind to the drug treatment.

Cell culture, transfection, differentiation, and determination of MAP2 levels: PC12 cells, clone 615 from ATCC, were maintained in DMEM medium, supplemented with 10\% fetal bovine serum (FBS) and 5\% horse serum (HS), containing penicillin/streptomycin and glutamine. For the experiments, the cells were transferred to 12 -well plates, and $24 \mathrm{~h}$ later, the cultivation medium was changed to DMEM $0.5 \%$ FBS at a density of $5 \times 10^{5}$ cells/well. Twentyfour hours later, the cells were transfected with a mixture of lipofectamine $2.5 \%$ in OptiMEM medium and $2 \mathrm{ug}$ of plasmids of 4 different interference sequences (shRNA) for NOS2 (0.5 $\mu \mathrm{g}$ of each sequence; Origene, \#TR709254, Rockville, MD, USA). Twenty-four hours after transfection, the cultivation medium was changed, and the cells were incubated with $\mathrm{KCl}$ (25 $\mathrm{mM}$ ) for 5 days. The levels of microtubule-associated protein 2 (MAP2) were determined by direct ELISA. Briefly, the samples $(120 \mu \mathrm{g}$ of total protein) were incubated in transparent 96well U-shaped plates overnight at $4^{\circ} \mathrm{C}$. Following blockade with $1 \%$ BSA in PBST, antibody against MAP2 (Millipore, \#AB5622, Darmstadt, Germany) was incubated overnight at $4^{\circ} \mathrm{C}$. The development of color following incubation with anti-rabbit IgG-HRP and BM Blue POD substrate (Roche Diagnostics, Espoo, Finland) was stopped by $1 \mathrm{M} \mathrm{HCl}$ and the color intensity was read at $450 \mathrm{~nm}$. The sample readouts, discounting the blank values, were expressed as percentage of the control-group (scrambled).

\section{Experimental design}

Time course of drug treatment effect in BB: independent cohorts of NOS2 KO male and female mice (8-9 weeks of age at the beginning of the experiment) were scored for BB and received 
139

140

141

142

143

144

145

146

147

148

149

150

151

152

153

154

155

156

157

158

159

160

161

162

163

164

165

166

167

168

169

difference was observed between males and females regarding the responsiveness to clomipramine, we opted to use only female mice in the subsequent experiments. Thus, a separate cohort of female NOS2 KO mice received memantine $(1 \mathrm{mg} / \mathrm{kg})$ for 20 days in the drinking water. The BB was scored at the start of the treatment and monitored every 5 days until the end of the experiment.

Rescue of BB by partial expression of NOS2: NOS2 haploinsufficient animals were obtained by crossing of NOS2 KO and WT in two cohorts: first KO sire and WT dam, second WT sire and KO dam. Age matched pups from NOS2 KO parents were generated as controls. The level of BB in the offspring (males and females) was observed from the 2nd to 9th week-of-age.

Repetitive behavior in NOS2 KO and WT mice: female NOS2 KO and WT were submitted to the actimeter for $15 \mathrm{~min}$. The total number of interruptions of the infrared beams was considered as total activity (Casarejos et al., 2013). The number of repetitive movements (including stereotypies and grooming) were also counted by the apparatus and normalized by the total activity, therefore expressed as percentage of repetitive behavior.

Effect of clomipramine on NOS2 KO repetitive behavior: this experiment was designed to address if the clomipramine treatment also modifies other phenotypic characteristics of NOS2 $\mathrm{KO}$, ie increased repetitive movements; as well as a possible effect in animals' total activity. To this aim, female NOS2 KO received clomipramine $(10 \mathrm{mg} / \mathrm{kg} /$ day, in the drinking water $)$ or vehicle during 14 days. On day 13, half of the vehicle-treated group received clomipramine in the drinking water. Therefore, the following groups were obtained: vehicle, acute clomipramine, and repeated clomipramine.

Role for NOS2 in activity-induced expression of MAP2 in PC12 cells: PC12 cells, transfected with NOS2 shRNA or scramble (non-coding sequence), were differentiated in $25 \mathrm{mM} \mathrm{KCl}$ for 5 days. At day 5, the cells were lysed and the levels of MAP2 determined by ELISA.

Statistical analysis: experiments were analyzed by one- or two-way ANOVA (considering drug treatment or genotype, and time as factors) or Student's t test. The Fisher's LSD post hoc test 
170 was used when appropriate. Unless otherwise stated, all data is expressed as Mean/SEM. Values

171 of $\mathrm{p}<0.05$ were set as significant.

172

173

\section{Results}

174

\section{Time course of drug treatment effect in BB}

175

As shown in fig $1 b-d$, there is a significant effect of clomipramine treatment on BB

in both males $[\mathrm{F}(1,18)=27.03 ; \mathrm{p}<0.0001]$ and females $[\mathrm{F}(1,8)=29.04, \mathrm{p}=0.0007]$. The post hoc analysis (Fisher's LSD) indicates a significant difference between clomipramine and vehicle treated groups at days 10, 15, and 20 for both males $(\mathrm{p}<0.0001$ for all) and females $(\mathrm{p}=0.0011$; 0.0038 and 0.0038 , respectively). The treatment with memantine, only performed in females, was also effective on $\mathrm{BB}[\mathrm{F}(1,12)=38.69, \mathrm{p}<0.0001]$, with significant difference from controls observed at days 10,15 and $20(p=0.0024$ for all $)$.

182

\section{Rescue of BB by partial expression of NOS2}

Analysis by two-way ANOVA indicates a significant effect of the genotype

$[\mathrm{F}(1,105)=99.87, \mathrm{p}<0.0001]$, the age $[\mathrm{F}(6,105)=34.14, \mathrm{p}<0.0001]$, and interaction between these factors $[\mathrm{F}(6.105)=5.23, \mathrm{p}<0.0001]$ on the barbering behavior exhibited by NOS2 KO

187

188

189

190

191

compared to NOS2 haploinsufficient animals from weaning age, fig 1d. Fisher's LSD test indicates significant differences starting from the 4th until 9th week-of-age $(p<0.05)$. No difference was observed at weaning age (3rd week) between pups from WT and NOS2 KO mothers.

\section{Repetitive behaviors in NOS2 KO and WT mice.}

Student's t test indicates a significant effect of genotype, with NOS2.KO females exhibiting reduced total activity $[\mathrm{t}(11)=4.79, \mathrm{p}=0.0006]$. However, an increase in the percentage of repetitive movements was observed $[\mathrm{t}(11)=2.69, \mathrm{p}=0.021]$, as found in fig $2 \mathrm{a}, \mathrm{b}$.

\section{Effect of clomipramine on NOS2 KO repetitive behavior}

As observed in fig 2, there was no significant effect of clomipramine treatment on (c) total activity in NOS2 KO females $[\mathrm{F}(2,14)=0.43, \mathrm{p}=0.66]$. However, repeated, but not acute, 
200 treatment with clomipramine decreased the percentage of repetitive movements (d) compared to 201 the control group $[F(2,14)=6.18, p=0.012]$.

202

203

204

205

206

207

208

209

210

211

212

213

214

215

216

217

218

219

220

221

222

223

224

225

226

227

228

229

230

\section{Role for NOS2 on activity-induced expression of MAP2 in PC12 cells}

The Student's t test indicates a significant effect of NOS2 silencing on the levels of MAP2 in PC12 cells [t(7) $=6.60, \mathrm{p}=0.0003]$, as found in fig $2 \mathrm{e}$.

\section{Discussion}

The present study suggests that the increased barbering behavior (BB) of NOS2 KO mice could be a putative model of trichotillomania (TTM). NOS2 KO exhibited increased BB after weaning (significantly higher at 4th week-of-age), and this phenotype increases until adulthood. TTM is an impulse control disorder, characterized by hair pulling or trimming. To our knowledge, there is no established animal model to study this disorder, which reflects in the poor pharmacotherapy and interventions available (Johnson \& El-Alfy, 2016). In animals, BB is a rare phenotype, with an incidence of approximately $2.5 \%$ in laboratory mice (Garner et al., 2004). In our facilities, BB frequency was even lower (less than $0.5 \%$ out of 500 animals checked). However, all NOS2 KO animals exhibited some degree of BB. This phenotype was described in the manufacturer's webpage (https://www.jax.org/strain/002596), and all attempts to eradicate $\mathrm{BB}$ in the colony resulted in loss of the genotype.

One of the few pharmacological options to treat TTM is clomipramine, a tricyclic antidepressant drug that preferentially inhibits the serotonin reuptake system (Swedo et al., 1989; Swedo, Lenane \& Leonard, 1993). In line with currently available data, our results indicate that repeated clomipramine administration was able to prevent the evolution of BB in NOS2 KO. Both males and females were equally responsive to the drug treatment. A possible confounding factor in the analysis of BB is the allobarbering instead of putatively selfbarbering. In the present case, we observed an incidence of $100 \%$ of BB in NOS2 KO in our colony; however, parts of the animal body only accessible by a conspecific, such as the back, were found barbered. This led us to conclude that the $\mathrm{BB}$ observed in these animals is a mixture of self- and allobarbering.

TTM is comorbid to several other psychiatric disorders, such as anxiety and obsessive-compulsive disorder (Grant et al., 2017). To investigate this association in NOS2 KO, the animals were submitted to the actimeter test, where both the total activity and the presence of spontaneous repetitive behavior were analyzed. Our results indicate a decreased activity of 
231 NOS2 KO associated with an increase in repetitive movements compared to WT animals. 232 Interestingly, clomipramine was only effective in reducing the last parameter, with no effect on 233 total activity. Despite reduced activity, this strain exhibits an antidepressant-like phenotype 234 (Montezuma et al., 2012), and a deficit in extinction of conditioned fear (Lisboa et al., 2015), but 235 no changes in repetitive behaviors was described. This mouse strain also presents decreased lung 236 tumorigenesis induced by urethane (Kisley et al., 2002). On the other hand, the lack of NOS2 237 does not change the animal's survival rate to bacterial lipopolysaccharide (LPS) (Laubach et al., 238 1995).

Compulsive-like behaviors have been observed in many transgenic animals. For 240 example, Francis Lee's group described increased grooming behavior in SLITRK KO mice 241 (Shmelkov et al., 2010). Rodents lacking the adaptor protein SAPAP3 also presented increased 242 grooming (Welch et al., 2007). Notwithstanding, this protein is responsible for anchoring 243 glutamatergic receptors in the cell membrane and multiple rare missense variants in its gene 244 sequence were found in OCD- and TTM-suffering patients (Züchner et al., 2009). Two other 245 studies pioneered the analysis of BB in transgenic mice, and described increased grooming and 246 BB in animals lacking the transcription factor HOXB8 (Greer \& Capecchi, 2002; Chen et al.,

247 248 249 250 251 252 253 254 255 256 257 258 259 260 261 2010). These two articles indicates that HOXB8 plays a major role in the excessive grooming phenotype, and is mainly expressed in components of CSTC. This is also an interesting possibility for NOS2. This enzyme level is highly modulated in cultured glial cells after several stimuli, such as LPS and interferon (Galea, Feinstein \& Reis, 1992; Garthwaite \& Boulton, 1995). Interestingly, the studies from Mario Capecchi's group points that the HOXB8 is expressed in bone-marrow-derived microglial cells. Thus in an intriguing speculative scenario, glial cells play a central role in the maturation and function of the CSTC components, leading to $\mathrm{BB}$ or excessive grooming. However, it is important to highlight that knocking out of NOS2 apparently does not lead to excessive grooming at the same extension of HOXB8 deletion. It is clear in the studies from Greer \& Capecchi (2010) as well as in Chen and colleagues (2010) that the animals exhibited extensive lesions in the snout area. This feature was absent in the NOS2 $\mathrm{KO}$, and the test used in the present study (actimeter) does not address if the increase in repetitive movements is a consequence of increased grooming behavior.

Our understanding of the neurobiology of TTM relies on few studies using brain image techniques suggesting a decrease in frontal cortical areas (mainly inferior frontal cortex) 
262 associated with an increase in striatal activity (Chamberlain et al., 2009; Fineberg et al., 2010). 263 As previously mentioned, the cortico-striatal-thalamic circuitry (CSTC) is a series of 264 reverberatory loops that integrate external signals and trigger motor programs in response. One 265 of the integrative structures in this circuitry is striatum, including its multiple subdivisions, and 266 disturbances in particular "hubs" in the CSTC are associated with different pathologies, from 267 Huntington's disease to obsessive-compulsive disorder, including trichotillomania [for review 268 see (Langen et al., 2011b,a)]. As a proof of concept, the treatment with the NMDA antagonist 269 memantine was equally effective as clomipramine, in preventing the evolution of BB in NOS2 270 KO mice. Taken together, our results suggest a potential therapeutic approach for TTM with 271 compounds acting on the glutamatergic system. In fact, drugs acting on decreasing glutamatergic 272 neurotransmission have been tested in TTM patients successfully. For example, N-acetyl273 cysteine was found to be effective in alleviating TTM symptoms in both double blind placebo274 controlled and case studies (Coric et al., 2007; Grant, Odlaug \& Kim, 2009; Rodrigues-Barata et 275 al., 2012). This compound also exhibited promising results in OCD suffering patients [for review 276 see (Oliver et al., 2015)]. Riluzole, another compound with antiglutamatergic properties, was 277 also found effective in OCD-related disorders (Emamzadehfard et al., 2016).

Data from literature linking NOS2 to putative neuronal developmental processes that 279 could lead to malfunctions in CSTC is also scarce. One of the few pieces of evidence about this 280 topic was provided by Arnhold and colleagues (2002) describing the role of NOS2 in the early 281 stages of neuronal maturation. They depicted a functional part for this enzyme in the cell 282 differentiation and migration in embryonic cortex, although not through the canonical pathway 283 of NO acting on soluble guanylate cyclase. Cultured cells from E14 rat embryo, when incubated 284 with selective NOS2 inhibitors, showed a lower number of microtubule-associated protein 285 (MAP2)-labeled neurons. Similarly, our data indicates that silencing NOS2 expression, leads to a 286 reduction in the levels of MAP2 in activity-dependent differentiation of PC12 cells (Banno et al., 2008). The role of NO in activity-dependent differentiation of PC12 cells has been described [for example (Nakagawa, Yoshida \& Miyamoto, 2000)]; however, the NOS1 isoform is implicated as 289 being responsible for this process. This discrepancy may be due to the culture conditions 290 between the studies. For example, Nakagawa and colleagues used a serum-free medium and $29145 \mathrm{mM}$ of $\mathrm{KCl}$ to differentiate the cells, while we rely on $0.5 \% \mathrm{FBS}$ and $25 \mathrm{mM}$ of $\mathrm{KCl}$. 292 Moreover, in the former study the authors cultivated a low density of PC12 cells (approximately 
29350 cells $/ \mathrm{cm}^{2}$; in a 96-well plate), while we used a high density from the beginning of the

294

295

296

297

298

299

300

301

302

303

304

305

306

307

308

309

310

311

312

313

314

315

316

317

318

319

320

321

322

323

324

325

326

327

328

329

330

331

332

333

334

experiment -125000 cells $/ \mathrm{cm}^{2}$ (in a 12 -well plate).

Conclusion: based on our data and the evidence in literature, we speculate that increased BB observed in NOS2.KO is putatively a resultant of inefficient inhibition of striatal motor programs by PFC. The lack of NOS2 in the early stages of cortical development could affect the maturation of cortical neurons, which in turn would lead to the described phenotype. The BB observed in these animals is sensitive to treatment with clomipramine and memantine, strengthening its role as a putative model of TTM. Further experiments will be necessary to clarify the role of NOS2 in the development of the BB phenotype and its functional consequences in the CSTC; as well as validate its sensitivity to other drugs.

Acknowledgement: The authors thank to Eleni T. Gomes (USP), Outi L. Nikkilä and Sulo J. Kolehmainen (UH) for their technical assistance.

\section{References:}

American Psychiatric Association. 2013. Diagnostic and Statistical Manual of Mental Disorders (DSM-5). American Psychiatric Pub.

Arnhold S., Faßbender A., Klinz F-J., Kruttwig K., Löhnig B., Andressen C., Addicks K. 2002. NOS-II is involved in early differentiation of murine cortical, retinal and ES cell-derived neurons - an immunocytochemical and functional approach. International Journal of Developmental Neuroscience: The Official Journal of the International Society for Developmental Neuroscience 20:83-92.

Banno Y., Nemoto S., Murakami M., Kimura M., Ueno Y., Ohguchi K., Hara A., Okano Y., Kitade Y., Onozuka M., Others. 2008. Depolarization-induced differentiation of PC12 cells is mediated by phospholipase D2 through the transcription factor CREB pathway. Journal of Neurochemistry 104:1372-1386.

Casarejos MJ., Perucho J., Gomez A., Muñoz MP., Fernandez-Estevez M., Sagredo O., Fernandez Ruiz J., Guzman M., de Yebenes JG., Mena MA. 2013. Natural cannabinoids improve dopamine neurotransmission and tau and amyloid pathology in a mouse model of tauopathy. Journal of Alzheimer's Disease: JAD 35:525-539.

Chamberlain SR., Odlaug BL., Boulougouris V., Fineberg NA., Grant JE. 2009. Trichotillomania: neurobiology and treatment. Neuroscience and Biobehavioral Reviews 33:831-842.

Chen S-K., Tvrdik P., Peden E., Cho S., Wu S., Spangrude G., Capecchi MR. 2010. Hematopoietic origin of pathological grooming in Hoxb8 mutant mice. Cell 141:775-785.

Christenson GA., Pyle RL., Mitchell JE. 1991. Estimated lifetime prevalence of trichotillomania in college students. The Journal of Clinical Psychiatry 52:415-417.

Coric V., Kelmendi B., Pittenger C., Wasylink S., Bloch MH., Green J. 2007. Beneficial effects of the antiglutamatergic agent riluzole in a patient diagnosed with trichotillomania. The Journal of Clinical Psychiatry $68: 170-171$.

Emamzadehfard S., Kamaloo A., Paydary K., Ahmadipour A., Zeinoddini A., Ghaleiha A., Mohammadinejad P., Zeinoddini A., Akhondzadeh S. 2016. Riluzole in augmentation of fluvoxamine for moderate to severe obsessive--compulsive disorder: Randomized, double-blind, placebo-controlled study. Psychiatry and Clinical Neurosciences 70:332-341.

Fineberg NA., Potenza MN., Chamberlain SR., Berlin HA., Menzies L., Bechara A., Sahakian BJ., Robbins TW., 

endophenotypes: a narrative review. Neuropsychopharmacology: Official Publication of The American College of Neuropsychopharmacology 35:591-604.

Galea E., Feinstein DL., Reis DJ. 1992. Induction of calcium-independent nitric oxide synthase activity in primary rat glial cultures. Proceedings of the National Academy of Sciences of the United States of America 89:1094510949.

Garner JP., Weisker SM., Dufour B., Mench JA. 2004. Barbering (fur and whisker trimming) by laboratory mice as a model of human trichotillomania and obsessive-compulsive spectrum disorders. Comparative Medicine $54: 216-224$.

Garthwaite J., Boulton CL. 1995. Nitric oxide signaling in the central nervous system. Annual Review of Physiology 57:683-706.

Grant JE., Odlaug BL., Kim SW. 2009. N-acetylcysteine, a glutamate modulator, in the treatment of trichotillomania: a double-blind, placebo-controlled study. Archives of General Psychiatry 66:756-763.

Grant JE., Redden SA., Leppink EW., Chamberlain SR. 2017. Trichotillomania and co-occurring anxiety. Comprehensive Psychiatry 72:1-5.

Greer JM., Capecchi MR. 2002. Hoxb8 is required for normal grooming behavior in mice. Neuron 33:23-34.

Johnson J., El-Alfy AT. 2016. Review of available studies of the neurobiology and pharmacotherapeutic management of trichotillomania. Journal of Advertising Research 7:169-184.

Kisley LR., Barrett BS., Bauer AK., Dwyer-Nield LD., Barthel B., Meyer AM., Thompson DC., Malkinson AM. 2002. Genetic ablation of inducible nitric oxide synthase decreases mouse lung tumorigenesis. Cancer Research 62:6850-6856.

Langen M., Durston S., Kas MJH., van Engeland H., Staal WG. 2011a. The neurobiology of repetitive behavior: .... and men. Neuroscience and Biobehavioral Reviews 35:356-365.

Langen M., Kas MJH., Staal WG., van Engeland H., Durston S. 2011b. The neurobiology of repetitive behavior: of mice.... Neuroscience and Biobehavioral Reviews 35:345-355.

Laubach VE., Shesely EG., Smithies O., Sherman PA. 1995. Mice lacking inducible nitric oxide synthase are not resistant to lipopolysaccharide-induced death. Proceedings of the National Academy of Sciences of the United States of America 92:10688-10692.

Lisboa SF., Gomes FV., Silva AL., Uliana DL., Camargo LHA., Guimarães FS., Cunha FQ., Joca SRL., Resstel LBM. 2015. Increased contextual fear conditioning in iNOS knockout mice: additional evidence for the involvement of nitric oxide in stress-related disorders and contribution of the endocannabinoid system. The International Journal of Neuropsychopharmacology / Official Scientific Journal of the Collegium Internationale Neuropsychopharmacologicum 18:pyv005.

McGuire JF., Ung D., Selles RR., Rahman O., Lewin AB., Murphy TK., Storch EA. 2014. Treating trichotillomania: a meta-analysis of treatment effects and moderators for behavior therapy and serotonin reuptake inhibitors. Journal of Psychiatric Research 58:76-83.

Montezuma K., Biojone C., Lisboa SF., Cunha FQ., Guimarães FS., Joca SRL. 2012. Inhibition of iNOS induces antidepressant-like effects in mice: pharmacological and genetic evidence. Neuropharmacology 62:485-491.

Nakagawa H., Yoshida M., Miyamoto S. 2000. Nitric oxide underlies the differentiation of PC12 cells induced by depolarization with high KCl. Journal of Biochemistry 127:113-119.

Oliver G., Dean O., Camfield D., Blair-West S., Ng C., Berk M., Sarris J. 2015. N-acetyl cysteine in the treatment of obsessive compulsive and related disorders: a systematic review. Clinical Psychopharmacology and Neuroscience: The Official Scientific Journal of The Korean College of Neuropsychopharmacology 13:12-24.

Rodrigues-Barata AR., Tosti A., Rodríguez-Pichardo A., Camacho-Martínez F. 2012. N-acetylcysteine in the treatment of trichotillomania. International Journal of Trichology 4:176-178.

Shmelkov SV., Hormigo A., Jing D., Proenca CC., Bath KG., Milde T., Shmelkov E., Kushner JS., Baljevic M., Dincheva I., Murphy AJ., Valenzuela DM., Gale NW., Yancopoulos GD., Ninan I., Lee FS., Rafii S. 2010. Slitrk5 deficiency impairs corticostriatal circuitry and leads to obsessive-compulsive-like behaviors in mice. Nature Medicine 16:598-602.

Swedo SE., Lenane MC., Leonard HL. 1993. Long-term treatment of trichotillomania (hair pulling). The New England Journal of Medicine 329:141-142.

Swedo SE., Leonard HL., Rapoport JL., Lenane MC., Goldberger EL., Cheslow DL. 1989. A double-blind comparison of clomipramine and desipramine in the treatment of trichotillomania (hair pulling). The New England Journal of Medicine 321:497-501.

Van Ameringen M., Mancini C., Patterson B., Bennett M., Oakman J. 2010. A randomized, double-blind, placebocontrolled trial of olanzapine in the treatment of trichotillomania. The Journal of Clinical Psychiatry 71:1336- 
391

392

393

394

395

396

397

398

399

400

401
1343.

Welch JM., Lu J., Rodriguiz RM., Trotta NC., Peca J., Ding J-D., Feliciano C., Chen M., Adams JP., Luo J., Dudek SM., Weinberg RJ., Calakos N., Wetsel WC., Feng G. 2007. Cortico-striatal synaptic defects and OCD-like behaviours in Sapap3-mutant mice. Nature 448:894-900.

Züchner S., Wendland JR., Ashley-Koch AE., Collins AL., Tran-Viet KN., Quinn K., Timpano KC., Cuccaro ML., Pericak-Vance MA., Steffens DC., Krishnan KR., Feng G., Murphy DL. 2009. Multiple rare SAPAP3 missense variants in trichotillomania and OCD. Molecular Psychiatry 14:6-9. 


\section{Figure legends}

403

404 Figure 1. (a) Phenotype of NOS2KO barbering behavior (BB), showing two vehicle- (panels a and b) and two clomipraminetreated (panels c and d) female NOS2KO. Effect of clomipramine (red squares; $10 \mathrm{mg} / \mathrm{kg}$ in the drinking water) on BB in males (e, $\mathrm{n}=10$ /group) and females (f; $\mathrm{n}=5$ /group) NOS2KO mice. (g) Effect of memantine (blue squares; $1 \mathrm{mg} / \mathrm{kg}$ in the drinking water) on BB in NOS2KO female mice ( $\mathrm{n}=7$ /group). (h) the partial rescue of NOS2 expression delays the onset and intensity of barbering behavior $\left(\mathrm{n}=7-10 /\right.$ group). ${ }^{*} \mathrm{p}<0.05$ from vehicle or NOS2.haploinsufficient group at the same time point. Photo credit: Plinio Cabrera Casarotto.

410

411 Figure 2. Reduced total activity (a) and increased percentage of repetitive behaviors (b) in NOS2KO females compared to WT (n

$412=6-7 /$ group $)$. Effect of clomipramine $(10 \mathrm{mg} / \mathrm{kg}$ in the drinking water) on total activity (c) and repetitive behaviors (d) in 413 NOS2KO females ( $\mathrm{n}=5$-6/group). (e) The silencing of NOS2 compromises the expression of MAP2 in KCl-induced 414 differentiation of PC12 cells ( $\mathrm{n}=4-5 /$ group). ${ }^{*} \mathrm{p}<0.05$ from WT, scrambled ( $\mathrm{scr}$ ) or vehicle-treated group.

415

416 


\section{Figure 1}

Rescue of barbering behavior in NOS2.KO

(a) phenotype of NOS2KO barbering behavior (BB), showing two vehicle- (panels a and b) and two clomipramine-treated (panels c and d) female NOS2KO. Effect of clomipramine (red squares; $10 \mathrm{mg} / \mathrm{kg}$ in the drinking water) on BB in males (e, $n=10 / \mathrm{group}$ ) and females ( $\mathrm{f} ; \mathrm{n}$ $=5 /$ group) NOS2KO mice. $(\mathrm{g}$ ) effect of memantine (blue squares; $1 \mathrm{mg} / \mathrm{kg}$ in the drinking water) on BB in NOS2KO female mice ( $n=7 /$ group). (h) the partial rescue of NOS2 expression delays the onset and intensity of barbering behavior ( $n=7-10 /$ group). ${ }^{*} p<0.05$ from vehicle or NOS2.haploinsufficient group at the same time point. Photo credit: Plinio Cabrera Casarotto.

a
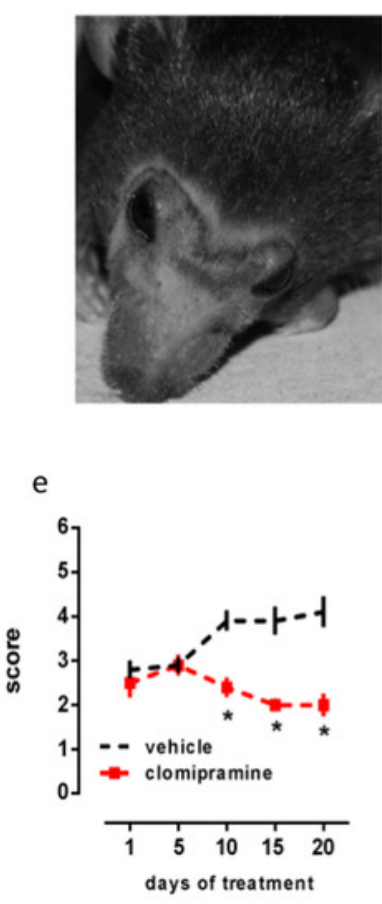

b

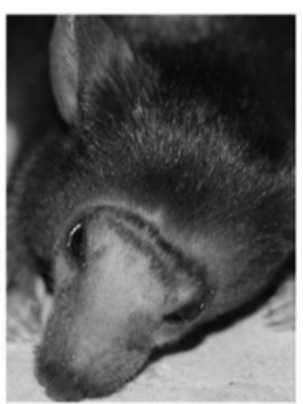

f

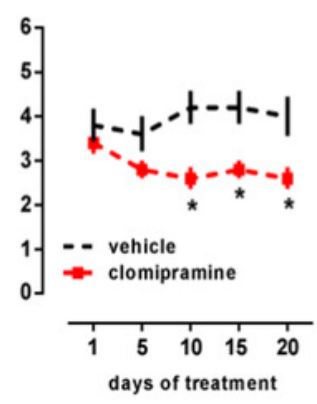

c

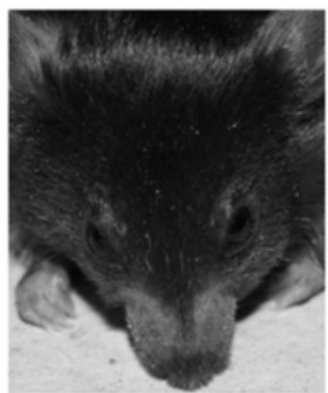

g

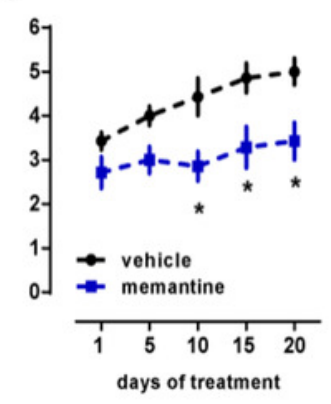

d

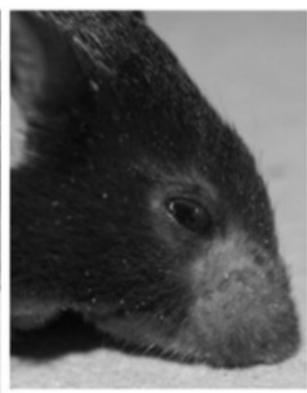

$\mathrm{h}$

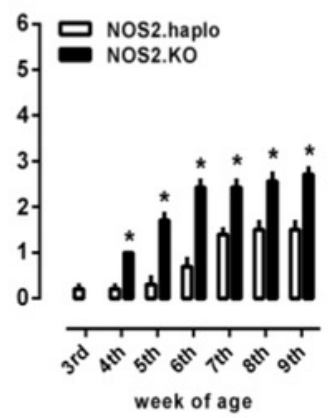


Figure 2

Repetitive and locomotor behavior of NOS2.KO and WT, and effect of siNOS2 in PC12 cells MAP2 expression.

Reduced total activity (a) and increased percentage of repetitive behaviors (b) in NOS2KO females compared to WT ( $n=6-7 / g r o u p)$. Effect of clomipramine (10 mg/kg in the drinking water) on total activity (c) and repetitive behaviors (d) in NOS2KO females ( $n=5$-6/group).

(e) the silencing of NOS2 compromises the expression of MAP2 in $\mathrm{KCl}$-induced differentiation of PC12 cells ( $n=4-5 / g r o u p) .{ }^{*} p<0.05$ from WT, scrambled ( $\left.s c r\right)$ or vehicle-treated group.
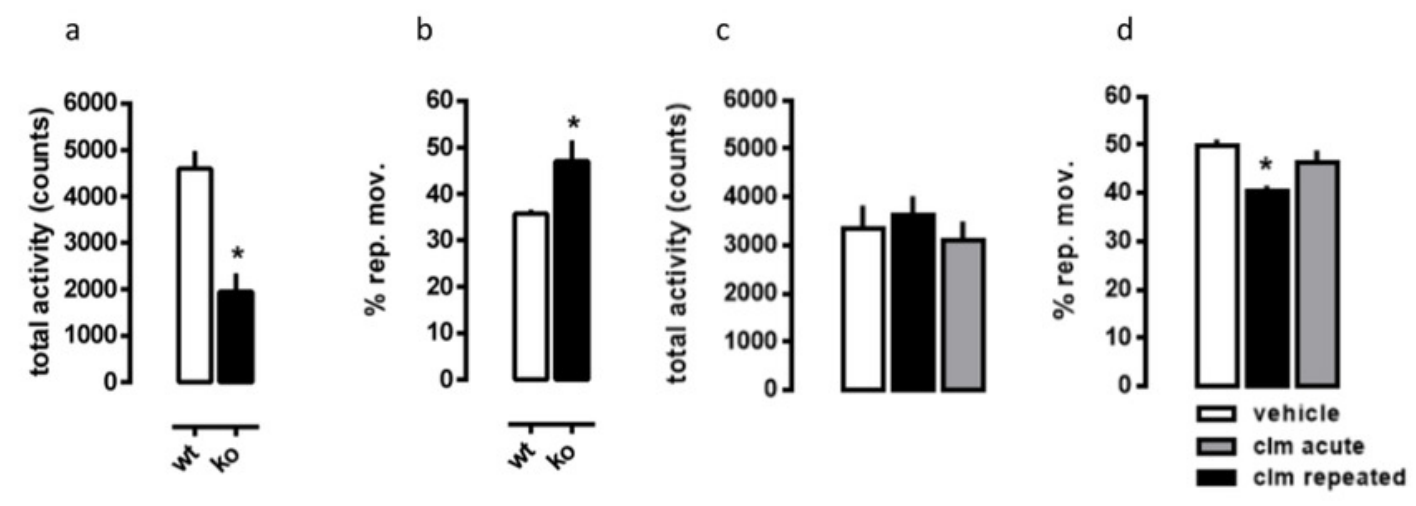

e

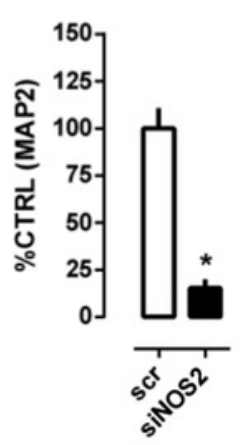




\section{Table 1 (on next page)}

Score for barbering behavior in NOS2.KO 
1 Table 1. Score for barbering behavior. Based on Garner et al 2004.

\begin{tabular}{|cc|}
\hline Area affected & score \\
\hline No hair loss & 0 \\
\hline Loss of whiskers & +1 \\
\hline Hair loss in snout & +1 \\
\hline Hair loss in eye area & +1 \\
\hline Hair loss in forehead & +1 \\
\hline Hair loss in chest/neck & +1 \\
\hline Hair loss in back & +1 \\
\hline
\end{tabular}

2 